\title{
Autotrophs' challenge to Dynamic Energy Budget theory: Comment on "Physics of metabolic organization" by Marko Jusup et al.
}

\author{
Sunčana Geček \\ Rudjer Bošković Institute, Division for Marine and Environmental Research, POB 180, Bijenička 54, HR-10 000 Zagreb, Croatia
}

Received 11 January 2017; accepted 16 January 2017

Available online 19 January 2017

Communicated by J. Fontanari

Jusup and colleagues in the recent review on physics of metabolic organization [1] discuss in detail motivational considerations and common assumptions of Dynamic Energy Budget (DEB) theory, supply readers with a practical guide to DEB-based modeling, demonstrate the construction and dynamics of the standard DEB model, and illustrate several applications. The authors make a step forward from the existing literature by seamlessly bridging over the dichotomy between (i) thermodynamic foundations of the theory (which are often more accessible and understandable to physicists and mathematicians), and (ii) the resulting bioenergetic models (mostly used by biologists in real-world applications).

Being environmental/ecosystem modeler with strong physical and mathematical background (but with no particular expertize in DEB modeling), I found the theoretical foundations presented in such a way very appealing and simple enough to follow. However, I do wish for more comprehensive information on DEB theory and application on autotrophs. Autotrophs are of primary concern to ecosystem modelers because they provide primary production on which all heterotrophs, directly or indirectly, rely for food. Secondary productivity by heterotrophs is only approximately $10 \%$ that of the primary productivity upon which it is based [2,3], making -for instance- phytoplankton a key player in aquatic ecosystem functioning. Key challenges in my field include coupling spatially explicit physicochemical models to biological models, and such couplings are often impossible without a model of primary producers.

Typically used mechanistic and/or quota-based models for phytoplankton growth [4-15], when forced by anthropogenic pressures (including climate change), struggle to provide reliable predictions: simpler models and semiempirical models do not correctly capture phytoplankton dynamics in a changing environment; complex models encounter problems of calibration and validation due to high number of variables and parameters; and both type of models struggle to integrate with models of energy flow on higher trophic levels, or hydrodynamical and chemical input-models on lower levels. The inability to provide reliable predictions is not only an academic issue - people's livelihoods and lives depend on our ability to predict (and therefore possibly prevent) large-scale events such as (i) harmful algal blooms that can lead to fish kills and/or paralytic shellfish poisoning, (ii) phytoplankton blooms leading to anoxia (a problem both in the wild and in aquaculture) and (iii) climate-driven changes in phytoplankton communities generating perturbations in fisheries and other marine systems.

DOI of original article: http://dx.doi.org/10.1016/j.plrev.2016.09.001.

E-mail address: suncana@irb.hr. 
DEB models are mechanistic and, therefore, could provide more reliable predictions of individual response in future environments. Furthermore, the standard DEB model for heterotrophs specifies organisms in terms of a small number of variables (in comparison to other mechanistic models) capturing fundamental metabolic processes common to all life. Although the number of parameters may seem daunting, DEB models utilize the parameters - with only 1.5 parameter per process [16] - extremely efficiently. Therefore, DEB models seem to be the tool I have been looking for in my work. However, even though as of the first quarter of 2016 more than 500 peer-reviewed papers on DEB and its applications have been published [1,17], papers on phytoplankton DEB models are few (but see [18-20]).

Given the importance of primary production, and the fact that theoretical background for autotrophs has been mostly set (at least since 2009 [21]), the lack of progress in DEB-based phytoplankton models is surprising. Even more surprising is the apparent fact that not a single set of DEB parameters in a database of 416 species describes an autotroph $[1,22]$. The broader community of ecosystem modelers rarely incorporates DEB theory into its palette of simulation methods [23,24], and one of the reasons may be this lack of "ready to use" DEB based models of primary production, which are crucial for proper ecosystem-model functioning. Furthermore, my (admittedly limited) scan of the existing phytoplankton DEB models suggests the existing DEB models for autotrophs could be ill-suited for integration with spatially explicit physico-chemical models. The autotroph DEB models seem to be an order of magnitude more complex and computationally demanding than standard DEB models, and focus on a single species. Estimates of primary productivity, however, require assemblages of species and should have minimal computing power requirements because of the large number of cells and timesteps required for the physico-chemical models. Hence, I would be interested to know more about current challenges in bioenergetic modeling of primary producers in aquatic ecosystems, particularly:

(i) Can DEB theory form a basis for an efficient phytoplankton and algal community dynamics model?

(ii) How much complexity is required to include independently acquired substrates (light energy, carbon, nutritive salts) and multi-reserve system, in terms of:

(a) Numerical costs of computation and numerical stability; and

(b) Number of parameters that need to be assessed by inverse calibration methods?

(iii) How do the theoretical foundation and numerical features differ form currently used mechanistic and quota-based models of phytoplankton growth?

(iv) Whether, and how, can we integrate DEB-based models of primary production into the larger context of food-web models, ecosystem models and hydrodynamical or transport models?

I hope that the DEB community realizes the need for DEB modeling of autotrophs, and provides a practical way of integrating DEB (or DEB-informed) models of autotrophs into spatially explicit physico-chemical models. The models based on DEB theory should be adopted more often by modelers outside of the "DEB community", because the mechanisms of DEB models apply universally, and the models "speak" the universal language of energy. This universality is acknowledged by authors in the very first sentence of the Abstract: "We review the most comprehensive metabolic theory of life existing to date". I'm looking forward for continuance of excellent work by the DEB community, and a future review that will include autotrophs (primary producers) as "life", too.

\section{References}

[1] Jusup M, Sousa T, Domingos T, Labinac V, Marn N, Wang Z, et al. Physics of metabolic organization. Phys Life Rev 2017;20:1-39. http://dx.doi.org/10.1016/j.plrev.2016.09.001 [in this issue].

[2] Pauly D, Christensen V. Primary production required to sustain global fisheries. Nature 1995;374(6519):255-7.

[3] Townsend C, Begon M, Harper J. Essentials of ecology. 3rd edition. Blackwell Publishing; 2008.

[4] Legović T, Cruzado A. A model of phytoplankton growth on multiple nutrients based on the Michaelis-Menten-Monod uptake, Droop's growth and Liebig's law. Ecol Model 1997;99(1):19-31.

[5] Zonneveld C. A cell-based model for the chlorophyll a to carbon ratio in phytoplankton. Ecol Model 1998;113(1-3):55-70.

[6] Geider R, MacIntyre H, Kana T. A dynamic regulatory model of phytoplanktonic acclimation to light, nutrients, and temperature. Limnol Oceanogr 1998;43(4):679-94.

[7] Flynn K. A mechanistic model for describing dynamic multi-nutrient, light, temperature interactions in phytoplankton. J Plankton Res 2001;23(9):977-97.

[8] Flynn K, Marshall H, Geider R. A comparison of two N-irradiance interaction models of phytoplankton growth. Limnol Oceanogr 2001;46(7):1794-802. 
[9] Klausmeier C, Litchman E, Daufreshna T, Levin S. Optimal nitrogen-to-phosphorus stoichiometry of phytoplankton. Nature 2004;429(6988):171-4.

[10] Pahlow M. Linking chlorophyll-nutrient dynamics to the Redfield N:C ratio with a model of optimal phytoplankton growth. Mar Ecol Prog Ser 2005;287:33-43, cited by (since 1996) 41.

[11] Armstrong R. Optimality-based modeling of nitrogen allocation and photoacclimation in photosynthesis. Deep-Sea Res, Part 2, Top Stud Oceanogr 2006;53(5-7):513-31.

[12] Smith S, Yamanaka Y. Optimization-based model of multinutrient uptake kinetics. Limnol Oceanogr 2007;52(4):1545-58.

[13] Ross O, Geider R. New cell-based model of photosynthesis and photo-acclimation: accumulation and mobilisation of energy reserves in phytoplankton. Mar Ecol Prog Ser 2009;383:53-71.

[14] Pahlow M, Oschlies A. Chain model of phytoplankton P, N and light colimitation. Mar Ecol Prog Ser 2009;376:69-83.

[15] Bonachela J, Allison S, Martiny A, Levin S. A model for variable phytoplankton stoichiometry based on cell protein regulation. Biogeosciences 2013;10(6):4341-56.

[16] Kearney M, Domingos T, Nisbet R. Dynamic Energy Budget theory: an efficient and general theory for ecology. Bioscience 2015;65(4):341.

[17] Bibliography of DEB papers, http://www.bio.vu.nl/thb/deb/DEB_papers.pdf. Accessed: 02 January 2017.

[18] Bruggeman J, Kooijman S. A biodiversity-inspired approach to aquatic ecosystem modeling. Limnol Oceanogr 2007;52(4):1533-44.

[19] Muller E, Ananthasubramaniam B, Klanjšček T, Nisbet R. Entrainment of cell division in phytoplankton with dynamic energy budgets. J Sea Res 2011;66(4):447-55.

[20] Muller E. Synthesizing units as modeling tool for photosynthesizing organisms with photoinhibition and nutrient limitation. Ecol Model 2011;222(3):637-44.

[21] Kooijman S. Dynamic Energy Budget theory for metabolic organisation. 3rd edition. Cambridge University Press; 2009.

[22] Add-my-Pet species list, http://www.bio.vu.n1/thb/deb/deblab/add_my_pet/species_list.html. Accessed: 02 January 2017.

[23] Ledder G. The basic dynamic energy budget model and some implications. Lett Biomath 2014;1(2):221-33.

[24] Janssen A, Arhonditsis G, Beusen A, Bolding K, Bruce L, Bruggeman J, et al. Exploring, exploiting and evolving diversity of aquatic ecosystem models: a community perspective. Aquat Ecol 2015;49(4):513-48. 